\title{
La integración de servicios sociales y de empleo en el debate entre protección y activación
}

\author{
Miguel Laparra \\ Laureano Martínez Sordoni \\ Universidad Pública de Navarra \\ laparra@unavarra.es; laureano.martinez@unavarra.es
}

\section{Resumen}

La integración de servicios es una de las principales vías de reforma del estado de bienestar que ha promovido Europa para evitar la fragmentación de sus sistemas de protección social y dar respuestas más eficaces a las necesidades de los sectores más vulnerables de la población. En el ámbito de los servicios sociales y de empleo, la integración tiene por objeto además potenciar la activación de los perceptores de prestaciones sociales y abre el debate en cuanto a los efectos de desprotección y control social que pueda implicar. Las reformas han tenido distinto alcance y orientación en cada país. El objetivo de este artículo es explorar las potencialidades y limitaciones que esta integración presenta en el caso español y profundizar el análisis de las reformas adoptadas en Navarra. Este caso muestra la viabilidad de una reforma orientada a potenciar la protección social de los sectores más vulnerables, a la vez que se refuerzan los mecanismos de activación y los procesos de inserción social y laboral, lo que contradice la supuesta oposición entre ambas dinámicas. En esto, la integración de los servicios sociales y de empleo y la introducción de un modelo de intervención centrada en la persona, a través del proyecto piloto ERSISI, han desempeñado un papel fundamental.

Palabras clave: integración de servicios; inclusión activa; rentas mínimas; empleo; activación; reformas estado de bienestar; políticas sociales 
Miguel Laparra; Laureano Martínez Sordoni

Abstract. The integration of social and employment services into the debate between protection and activation

The integration of social services is one of the main ways of reforming the Welfare State promoted in Europe. These reforms are aimed at avoiding the fragmentation of social protection systems and providing more effective responses to the needs of the most vulnerable people. Regarding social and employment services, integration reforms also aims to strengthen the activation of social benefit recipients and opens the debate on the effects of lack of social protection and control that it may imply. The reforms have had different scope and orientation in each country. The aim of this article is to explore the potentialities and limitations of service integration in Spain, deepening the analysis of the reforms undertaken in the region of Navarre. This case shows the viability of a reform aimed at strengthening social protection for the most vulnerable sectors while reinforcing activation mechanisms and social and labour market inclusion processes, thus calling into question the supposed opposition between the two dynamics. In this respect, the integrated delivery of social and employment services and the introduction of a person-centered intervention model, which was made through the ERSISI pilot project, have played a fundamental role.

Keywords: service integration; active inclusion; minimum income; employment, activation; Welfare State reforms; social policies

\section{Sumario}

1. Introducción

2. Las lecciones del análisis de las experiencias europeas

3. La evidencia empírica de una población que requiere la atención conjunta de servicios sociales y de empleo en España

4. Escasez de intentos y debilidad de los objetivos planteados en España
5. Navarra, una reforma de orientación socialdemócrata: amplia protección e inclusión social activa centrada en la persona

Conclusiones

Agradecimiento

Referencias bibliográfica

\section{Introducción}

En las últimas décadas, las sociedades europeas han experimentado un conjunto de transformaciones económicas y sociales que han conducido a la reorientación de los objetivos de sus sistemas de bienestar. En el ámbito de la garantía de ingresos, se diferenciaba tradicionalmente entre los programas diseñados para cubrir los periodos relativamente cortos de desempleo del sustentador principal, por un lado, y aquellos orientados a ofrecer asistencia social para quienes no estaban en condiciones de trabajar, por otro. Esta diferenciación no ha mostrado ser adecuada ante las transformaciones que vienen teniendo lugar desde finales del siglo xx en los mercados de trabajo. El aumento del desempleo de larga duración, la alta rotación entre empleo y desempleo, el fenómeno de la pobreza en el empleo o la segmentación de los mercados de trabajo - por 
mencionar los cambios más destacados_ - han hecho menos nítida la separación de colectivos o perfiles en función de su relación con el empleo como criterio delimitador. Esto ha supuesto la necesidad de dar respuesta a un conjunto de problemáticas no contempladas en el diseño tradicional de las políticas sociales.

En el marco de esas transformaciones, y en un contexto marcado por la contención del gasto público y la disciplina fiscal, el eje clásico de la protección social, conformado por las políticas de garantía de ingresos, se ha visto progresivamente acompañado por medidas de activación para el empleo, orientadas al retorno al mercado de trabajo de la población desempleada e inactiva, lo cual ha supuesto una tensión permanente entre protección y activación (Bonoli, 2013).

Como consecuencia de esos cambios en los objetivos de las políticas sociales, la fragmentación entre las distintas instituciones que conforman los sistemas de protección social ha emergido como una problemática de primer orden. Diferentes áreas de las políticas sociales — principalmente los sistemas de rentas mínimas, las políticas activas de empleo y los servicios sociales- suelen corresponder a distintos niveles gubernamentales (estatal, regional, local), lo que da lugar a una fragmentación vertical. Al mismo tiempo, las diferentes áreas del sistema pueden ser gestionadas por distintas agencias u organismos públicos, con la participación, también, de entidades privadas, de modo que se generan distintos grados de fragmentación horizontal. Por ello, las asimetrías, la discontinuidad, la duplicidad o las lagunas entre los diferentes tipos de programas de garantía de ingresos y los programas de inclusión o activación para el empleo han sido señalados como obstáculos para la creación de círculos virtuosos entre garantía de rentas, servicios (sociales, vivienda, salud) y empleo o formación (Rodríguez Cabrero, 2011).

Para dar respuesta a ese problema, la mayor parte de los países europeos han adoptado reformas en sus políticas, orientadas a mejorar la coordinación o integración de servicios sociales y de empleo. La integración de servicios se presenta de esta forma como una alternativa para mejorar la capacidad de respuesta institucional a los perfiles que acumulan problemáticas diversas, lo que mejora la velocidad de respuesta, simplifica los procesos de toma de decisiones para cada caso, evita duplicidades o solapamientos y reduce problemas de coordinación entre distintas áreas.

La experiencia acumulada en las últimas dos décadas arroja una diversidad de tipos de reformas, que van desde las de gran alcance, con la fusión de agencias previamente autónomas — comprenden diversas áreas y niveles de las políticas - , pasando por instancias intermedias - como la creación de ventanillas únicas-, hasta reformas más gradualistas y locales, caracterizadas por la colaboración interprofesional entre distintas áreas.

La mayor parte de las reformas analizadas en Europa corresponden a los modelos de bienestar nórdico, continental y anglosajón, pero también existen experiencias de integración analizadas en el resto de países agrupados en el modelo de bienestar mediterráneo, como el caso italiano (Catalano et al., 2016; Genova, 2008), el portugués (Scharle, 2018) o el griego (Munday, 2007). Existen escasas evidencias, en cambio, sobre el caso español. Esto se debería, 
en parte, a que la integración de servicios sociales y de empleo no ha ocupado un lugar relevante en la agenda de reformas, a pesar de la insistencia del Consejo Europeo, que, desde 2014, reiteradamente ha transmitido a España su recomendación de mejorar la coordinación de estos servicios como vía para mejorar su efectividad (Consejo Europeo, 2014).

Si bien desde entonces se han realizado proyectos orientados a la mejora de la coordinación entre servicios, principalmente en el ámbito local (o comarcal en el caso del País Vasco) (Ferran Zubillaga et al., 2019; Pérez Eransus y Martínez Virto, 2020), el caso navarro, una experiencia local y regional, gradualista y basada en transformaciones de su modelo de renta mínima, en los métodos de intervención profesionales y los procedimientos administrativos, es el que más ha avanzado en la coordinación de los principales componentes de sus políticas de inclusión. Por ello, el objetivo de este artículo es analizar qué alcance tienen el tipo de experiencias de reformas más gradualistas y sobre qué bases institucionales pueden darse estas reformas en un país como España, a partir del análisis de un conjunto de medidas adoptadas en la Comunidad Foral de Navarra entre 2016 y 2019.

El artículo se divide en cuatro apartados. Inicialmente, se resumen las principales características de las reformas implementadas en Europa en lo referido a integración de servicios y a las distintas formas de abordar el debate entre protección y activación, y se señala el lugar que ocupa la experiencia analizada en ese marco. Seguidamente, se presentan, a partir de distintas fuentes de datos, evidencias sobre las características de la población usuaria de los servicios sociales y de empleo en España, para poner de manifiesto la existencia de un número significativo de casos que hacen uso de ambos sistemas, como indicador de la pertinencia y necesidad de un enfoque de atención integrada. En tercer lugar, se presenta un análisis de algunas experiencias en materia de integración de servicios sociales y de empleo en el caso español, donde queda de manifiesto el carácter parcial de este tipo de experiencias. Por último, se desarrollan los avances de la experiencia en Navarra en materia de integración de servicios y las medidas orientadas a garantizar coordinadamente el derecho a una garantía de ingresos con la incorporación sociolaboral, es decir, la forma en que esta comunidad ha abordado el debate entre protección y activación.

\section{Las lecciones del análisis de las experiencias europeas}

El contexto europeo muestra experiencias diversas en lo referido a las reformas de integración de servicios y al abordaje del debate sobre protección social y activación para el empleo. Muchos países iniciaron tempranamente reformas encaminadas a reorganizar y coordinar mejor los sectores que componen sus sistemas de protección social, tal como queda reflejado en el informe preparado por Munday (2007) para el Consejo Europeo. Más recientemente, y después de una importante producción científico-técnica en torno a este tema (Askim et al., 2011; Champion y Bonoli, 2011; Lara Montero et al., 2016; Minas, 
2016; OECD, 2015), un estudio encargado por la Comisión Europea aborda las principales reformas llevadas a cabo en Europa en los últimos años y pone el acento en los arreglos institucionales orientados a integrar la última red de protección social con otros ámbitos de los sistemas de bienestar, en particular con los de activación para el empleo (Scharle, 2018).

Una de las ideas clave que destaca el informe es la existencia de distintos modelos de integración. El estudio identifica, a partir del análisis de doce reformas en países europeos, dos grandes vías posibles para esas reformas, según el contexto institucional sobre el que se fueran a aplicar: una vía de reformas estructurales, que puede implicar la unificación de agencias administrativas y cambios en la distribución de competencias y responsabilidades entre el Estado y las entidades subestatales; y una vía que supone desarrollar el proceso de cooperación institucional entre los servicios sociales y de empleo y que deja un amplio margen para la acción local.

Del análisis de los casos se identifican los principales aspectos condicionantes para avanzar en un proceso de integración: los relacionados con la teoría de la path dependence — tradición de las burocracias y los modelos administrativos, cultura institucional, etcétera-, la existencia de un contexto político propicio - o bien un modelo político centralizado, o bien un amplio consenso político o una clara determinación de los agentes locales sobre el terreno-y la calidad de la Administración pública, entendida como su capacidad para conseguir los objetivos planteados políticamente. Por tanto, a la hora de introducir estas reformas, se recomienda atender el contexto institucional y el modelo político, desarrollar estrategias de formación y cualificación previa de los profesionales y cuidar el ritmo y la progresividad de las reformas en función de la calidad de la Administración pública (Scharle, 2018).

En el tipo de reformas más gradualistas, donde se preserva la autonomía de los servicios implicados, y que nos resulta de interés por el caso analizado en el artículo, el trabajo en equipos interprofesionales es un aspecto fundamental de la prestación de servicios integrados (Lara Montero et al., 2016). Por ello, para romper con las dinámicas de trabajo en «silos»o áreas estancas, desde el punto de vista organizacional se deben llevar a cabo acciones que afectan aspectos tanto «organizacionales» como «humanos». Entre los aspectos organizacionales, se encuentran cuestiones como la existencia de marcos normativos comunes, protocolos de trabajo, herramientas compartidas y el acceso a sistemas informáticos compartidos. Entre los aspectos humanos, se señala la importancia de tener una visión compartida, el desarrollo de una comunicación eficaz, la disponibilidad de tiempo para establecer relaciones, la definición de un liderazgo claro, la asignación de roles y tareas claramente definidas y el desarrollo de un lenguaje compartido.

Como se ha señalado, una cuestión transversal en las reformas de integración de servicios es la activación de las personas beneficiarias de prestaciones económicas de carácter asistencial — con prueba de necesidad — que funcionan como última red de protección para los sectores más vulnerables, como son los sistemas de rentas mínimas. 
La activación se ha asumido de una forma u otra en toda Europa como una tendencia común de las políticas de protección social y empleo (Bonoli, 2013). Como consecuencia de ello, en la mayoría de los países se ha condicionado cada vez más la protección social a comportamientos orientados al empleo, lo cual no ha dejado de suscitar debates tanto políticos como académicos en torno a la tensión entre protección y activación. Una buena prueba de este debate queda reflejada en el reciente número monográfico de la revista Social Policy and Administration (Fletcher, 2020). En él, es interesante comprobar cómo, más allá de esa tendencia común, pueden distinguirse concepciones y orientaciones muy distintas en su aplicación concreta: una más neoliberal y otra más socialdemócrata.

Los modelos más neoliberales, preferentemente en el ámbito anglosajón, han reforzado su carácter punitivo y sancionador - por ejemplo, con la retirada del $100 \%$ de la prestación hasta por tres años en el Reino Unido-, orientado a reducir el número de perceptores y el gasto social. Por ello se han calificado de "herramienta de vigilancia, coerción y castigo", de "violencia institucional» o "asesinato social» (Wright et al., 2020).

Por el contrario, en el modelo socialdemócrata, la activación no se entiende exclusivamente orientada al mercado de trabajo, sino que se concibe también una «activación social» que pretende superar las situaciones de aislamiento. Aquí las sanciones son mucho más reducidas y se aplican de forma discrecional por los profesionales, con una concepción pedagógica, de forma suave, evitando la desprotección, y orientadas por el mejor interés del usuario. Las actividades y el empleo se entienden positivas para el mantenimiento o la potenciación del capital humano (Sadeghi y Terum, 2020)

En lo que sigue mostraremos, a partir del caso navarro, cómo las políticas de integración de servicios sociales y de empleo gradualistas en el ámbito subestatal pueden ir también asociadas a concepciones de la activación más cercanas a este modelo socialdemócrata, incluso en un contexto estatal propio del modelo mediterráneo, como es el caso de España.

\section{La evidencia empírica de una población que requiere la atención conjunta de servicios sociales y de empleo en España}

En este punto queremos mostrar cómo en España se aprecia una realidad de población que comparte los servicios sociales y los de empleo, y que ese colectivo presenta mayores dificultades para la incorporación al empleo. Estas situaciones más complejas pueden explicarse tanto por factores estructurales como también por procesos de discriminación concretos. En otros casos, se han identificado factores más subjetivos, como la falta de redes sociales, las adicciones, los problemas de salud, el sobreendeudamiento, la baja cualificación, ciertas crisis vitales o las responsabilidades de cuidados de menores y personas mayores (Fernandez et al., 2016; RIS, 2020). En todos estos casos, las actuaciones segmentadas parecen no ayudar demasiado y, por ello, tiene sentido plantear algún tipo de integración de las actuaciones entre servicios 
sociales y de empleo en la línea que nos marca la experiencia de otros países europeos.

La propia dinámica de las necesidades de estas personas hace que efectivamente acaben recalando en ambos sistemas (servicios sociales y empleo) y que la intervención se esté dando de manera conjunta, aunque sin que se haya previsto un sistema general de coordinación o un mecanismo de comunicación, lo cual puede conducir a un importante grado de ineficacia e ineficiencia. De acuerdo con la última Encuesta sobre Integración y Necesidades Sociales de la Fundación Foessa, en 2018, en España había en torno a un millón de personas desempleadas que estaban inscritas en el servicio público de empleo y cuyas familias eran atendidas también por los servicios sociales públicos, lo que suponía el $22 \%$ de las personas atendidas en empleo y un $36 \%$ de las atendidas por servicios sociales en edad activa. Esta coincidencia en una parte de la población atendida se da en una proporción mucho mayor en los sectores más vulnerables y con problemáticas más intensas: unas 640.000 personas en edad activa que se encuentran en situación de exclusión social severa o pobreza monetaria severa ${ }^{1}$ eran atendidas a la vez por los servicios sociales y de empleo, lo que suponía el $47 \%$ de la población atendida por los servicios sociales públicos y el $45 \%$ de la atendida por los servicios públicos de empleo.

Con carácter general, puede apreciarse una mayor acumulación de dificultades y más presencia de algunos grupos con especialmente vulnerables en la población compartida por ambos sistemas que en la que aparece en uno solo de ellos: un nivel educativo más bajo (el $38 \%$ no alcanza el nivel de secundaria obligatoria); más presencia de la comunidad gitana (el 10,4\%, más de tres veces la población propia de empleo, cuando la presencia en el conjunto de la población española no llega al $2 \%$ ); más personas con limitaciones por su estado de salud (el $12 \%$, similar aquí a los que van solo a servicios sociales); más personas que sufren exclusión residencial (el $20 \%$ en barrios degradados). Este grupo atendido por los dos sistemas es claramente el que menos ingresos tiene: $3.300 €$ anuales por unidad de consumo de media, un $28,5 \%$ menos que las personas que acuden a los servicios de empleo. También es el que presenta un mayor nivel de exclusión social medido con el índice sintético de exclusión social de Foessa, un 23,4 \% más que en empleo. Esta acumulación de dificultades hace más necesario, como ya se ha dicho, el establecimiento de procesos de trabajo conjunto si se pretende tener resultados eficaces.

La experiencia de la gestión de las rentas mínimas ha llevado a conclusiones similares en cuanto a la existencia de muchas personas perceptoras en condiciones de incorporarse al mercado de trabajo, aunque en muchos casos con necesidad de apoyos sociales además de su promoción laboral. Especialmente en una crisis económica larga e intensa como la de 2007-2014, muchos sectores tradicionalmente alejados de los servicios sociales y con una relación habitual

1. Exclusión social severa: con un índice sintético de exclusión, construido a partir de 35 indicadores, que supera en 4 veces la media del conjunto de la sociedad. Pobreza severa: por debajo del $40 \%$ de la mediana de ingresos familiares equivalentes. 
Tabla 1. Características de la población en edad laboral y en situación de pobreza severa o exclusión social severa, según si es atendida por los servicios sociales públicos (SSP) y los servicios públicos de empleo (SPE), 2018 (\%)

\begin{tabular}{lrrr}
\hline & $\begin{array}{c}\text { Atendido solo } \\
\text { por SSP }\end{array}$ & $\begin{array}{r}\text { Atendido solo } \\
\text { por SPE }\end{array}$ & $\begin{array}{c}\text { Atendido por } \\
\text { SSP y por SPE }\end{array}$ \\
\hline Varón & 43,5 & 51,8 & 53,0 \\
Mujer & 56,7 & 48,0 & 47,0 \\
\hline Menos de 30 años & 33,8 & 24,1 & 19,4 \\
30-44 años & 34,6 & 34,6 & 37,0 \\
$45-64$ años & 31,6 & 41,3 & 43,8 \\
\hline Ni lee ni escribe & 2,4 & 0,4 & 0,5 \\
Inferior a Graduado Escolar o ESO & 33,1 & 22,4 & 37,4 \\
Graduado Escolar o en ESO, Bachiller elemental & 41,1 & 40,9 & 38,1 \\
BUP, FPI, FPII, Bachiller LOGSE, o superior & 17,8 & 26,1 & 19,4 \\
Diplomado, licenciado o superior & 5,6 & 10,2 & 4,6 \\
\hline Españoles y UE15 & 63,8 & 76,8 & 64,6 \\
Gitanos & 5,6 & 3,0 & 10,4 \\
Extranjeros incluidos EU12 & 30,8 & 20,0 & 24,9 \\
\hline Persona con limitaciones de salud & 12,3 & 6,2 & 11,9 \\
\hline Persona sola & 4,6 & 11,6 & 11,6 \\
De 2 a 4 miembros & 59,8 & 70,8 & 64,4 \\
5 y más miembros & 35,8 & 17,6 & 23,7 \\
Monoparental & 22,9 & 17,6 & 17,9 \\
\hline Barrio degradado, marginal & 18,1 & 10,5 & 19,9 \\
\hline Total & 100,0 & 100,0 & 100,0 \\
\hline Índice sintético de exclusión social & 5,706 & 5,237 & 6,49 \\
Ingresos por unidad de consumo (€/año) & 3.775 & 4.617 & 3.301 \\
\hline Funt: Elato & & & \\
\hline
\end{tabular}

Fuente: Elaboración propia a partir de la Encuesta sobre Integración Social y Necesidades Sociales 2018, de la Fundación Foessa.

con el mercado de trabajo tuvieron que recurrir a ellos. En el País Vasco, el $52 \%$ de los perceptores de la renta de garantía de ingresos (RGI) eran desempleados en edad activa, un $18 \%$ eran trabajadores con bajos salarios y solo un $30 \%$ estaban retirados del mercado de trabajo. Un $82 \%$ había tenido una experiencia laboral anterior (González Gago, 2018).

Los datos para Navarra nos dicen también que los Servicios Sociales de Base han considerado que solo son un tercio las unidades familiares perceptoras de renta garantizada $(\mathrm{RG})$ que no están en condiciones de incorporarse a un empleo. $^{2}$

El aumento de la pobreza entre las personas ocupadas (pobreza laboral) pone de relieve la existencia de otro colectivo que, aunque técnicamente no está en situación de desempleo, debería ser igualmente atendido por ambos

2. Datos del Departamento de Derechos Sociales del Gobierno de Navarra. 
sistemas. Un 35,6 \% de las unidades familiares perceptoras de renta garantizada (RG) en Navarra tienen ingresos por trabajo. De ellas, a dos de cada tres se les estarían aplicando estímulos al empleo (3.848 unidades familiares de un total de 5.586) (DGIyPS, 2020b). El hecho de que, en unas condiciones de precariedad laboral muy notables, el acceso al empleo no les permita salir del nivel de pobreza severa pone de manifiesto la necesidad de que los servicios sociales garanticen la protección económica de estas personas y de que los servicios de empleo sigan promocionando sus itinerarios laborales. En términos individuales, aun así, estamos hablando del $30 \%$ de perceptores en edad laboral que han conseguido algún contrato en términos anuales. Queda otra proporción importante, otro tercio, posiblemente más alejada del mercado de trabajo, pero no inempleable, sobre la que el trabajo conjunto y cercano de los servicios sociales y los servicios de empleo parece un requisito ineludible para poder avanzar en su inclusión social y laboral.

En la misma línea, los resultados del pilotaje de integración de servicios en Navarra $^{3}$ señalan que, dentro del colectivo de personas perceptoras de rentas mínimas, en torno a un $80 \%$ requería y estaba en condiciones de acceder a un itinerario de alta intensidad orientado al empleo. De ese total, aproximadamente la mitad, un 43,7 \% del total, requería servicios exclusivamente de activación para el empleo, y un $37,7 \%$, servicios integrados, es decir, perfiles que presentaban necesidades a ser atendidas por ambas agencias implicadas. El $20 \%$ restante solo requería recursos específicos de los servicios sociales o de salud.

Son coincidentes, por tanto, la información de la encuesta Foessa en el ámbito estatal, la información extraída de distintos programas de rentas mínimas y la información de proyectos piloto de integración como el ERSISI en Navarra. Hay un sector significativo de la población que tiene dificultades para incorporarse al mercado de trabajo, pero que podría hacerlo con una actuación integrada entre los servicios sociales y de empleo.

\section{Escasez de intentos y debilidad de los objetivos planteados en España}

A diferencia de la integración entre servicios sociales y sanitarios en España, que cuentan con experiencias relevantes (Álvarez Rosete, 2020; Garcés y Ródenas, 2015), la debilidad de los objetivos planteados en materia de integración de servicios sociales y de empleo es patente. Esto explica la escasa presencia que tiene el caso español en los estudios comparados en materia de integración o coordinación de servicios sociales y de empleo.

La estructura administrativa y la división competencial pueden ser algunas de las razones por las que estas experiencias son tan escasas. En las CCAA, los servicios sociales habitualmente se agrupan en una consejería propia, y las competencias de empleo se gestionan a menudo en los departamentos encargados de la política económica. En todos los casos se trata de contextos institucionales

3. Ver explicación del proyecto ERSISI (Enhancing the Right to Social Inclusion through Service Integration) más adelante. 
Tabla 2. Departamentos a los que se asignan las competencias de servicios sociales y de empleo en las distintas CCAA españolas, enero de 2020

\begin{tabular}{|c|c|c|}
\hline CCAA & Competencias de servicios sociales & Competencias de empleo \\
\hline Andalucía & $\begin{array}{l}\text { Igualdad, Políticas Sociales } \\
\text { y Conciliación, Salud y Familias }\end{array}$ & Empleo, Formación y Trabajo Autónomo \\
\hline Aragón & Ciudadanía y Derechos Sociales & Economía, Planificación y Empleo \\
\hline Asturias & Derechos Sociales y Bienestar & $\begin{array}{l}\text { Industria, Empleo y Promoción } \\
\text { Económica }\end{array}$ \\
\hline Islas Baleares & Asuntos Sociales y Deporte & Modelo Económico, Turismo y Trabajo \\
\hline Canarias & $\begin{array}{l}\text { Derechos Sociales, Igualdad, } \\
\text { Diversidad y Juventud }\end{array}$ & Economía, Conocimiento y Empleo \\
\hline Cantabria & \multicolumn{2}{|c|}{ Empleo y Políticas Sociales } \\
\hline $\begin{array}{l}\text { Castilla-La } \\
\text { Mancha }\end{array}$ & Bienestar Social & Economía, Empresas y Empleo \\
\hline Castilla y León & Familia e Igualdad de Oportunidades & Empleo e Industria \\
\hline Cataluña & \multicolumn{2}{|c|}{ Trabajo, Asuntos Sociales y Familias } \\
\hline C. Valenciana & Igualdad y Políticas Inclusivas & $\begin{array}{l}\text { Economía Sostenible, Sectores } \\
\text { Productivos, Comercio y Trabajo }\end{array}$ \\
\hline Extremadura & Sanidad y Servicios Sociales & Educación y Empleo \\
\hline Galicia & Política Social & Economía, Empleo e Industria \\
\hline La Rioja & Servicios Sociales y a la Ciudadanía & Educación y Cultura \\
\hline Madrid & $\begin{array}{l}\text { Políticas Sociales, Familias, Igualdad } \\
\text { y Natalidad }\end{array}$ & Economía, Empleo y Competitividad \\
\hline Murcia & $\begin{array}{l}\text { Mujer, Igualdad, LGTBI, Familias } \\
\text { y Política Social }\end{array}$ & Empleo, Investigación y Universidades \\
\hline Navarra & \multicolumn{2}{|c|}{ Derechos Sociales } \\
\hline País Vasco & \multicolumn{2}{|c|}{ Empleo y Políticas Sociales } \\
\hline
\end{tabular}

Fuente: elaboración propia según la información facilitada por las CCAA.

bastante alejados que no han facilitado el diálogo entre los servicios sociales y las políticas activas de empleo.

Así, a comienzos de 2020, tan solo había cuatro CCAA en las que coincidían en un mismo departamento empleo y servicios sociales: País Vasco, ${ }^{4}$ Cataluña, Navarra y Cantabria. En las dos primeras, las rentas mínimas son gestionadas desde los servicios de empleo, y en las otras dos, desde los servicios sociales. Sin embargo, dentro del departamento, servicios sociales y empleo tienen siempre estructuras separadas, habitualmente con organismos autónomos.

4. Después de las elecciones de 2020, con la configuración de un nuevo Gobierno, también en el País Vasco empleo y servicios sociales se ubican en distintos departamentos. 
Además, en una de ellas, el País Vasco, esta coincidencia departamental oculta que la organización de los servicios sociales se realiza preferentemente desde el nivel subautonómico de las diputaciones forales y los ayuntamientos, alejada por tanto de la gestión de las políticas de empleo.

En el País Vasco, el traspaso de la gestión de la renta de garantía de ingresos al servicio público de empleo, Lanbide, acometida en 2011, se ha presentado como una práctica de one-stop-shop. Este traspaso significó una mayor implicación de los servicios de empleo con los perceptores y una liberación de estas tareas para los servicios sociales. El aumento de las tasas de salida (en torno al $10 \%$ antes de la reforma y en un $19 \%$ después) y la reducción de las tasas de pobreza a un ritmo superior a las regiones del entorno se han mostrado como evidencias de los efectos positivos de esta reforma en la activación. Pese a la mejora de estos indicadores, la reforma no ha avanzado en la cooperación entre servicios sociales y empleo para la atención a esta población, algo que se pretendía a través de una aplicación informática compartida, que, al menos de momento, es raramente utilizada (González Gago, 2018). Más todavía, se ha detectado una reducción de la implicación de los servicios sociales municipales en la atención social a las personas perceptoras de la RGI que ya no acuden en muchos casos, así como problemas de falta de continuidad en la atención y falta de consideración de las dificultades sociales en las suspensiones de la prestación. Mientras, los servicios de empleo ven la nueva tarea «como una losa que ha caído al sistema" y muestran dificultades para atender a los sectores más excluidos (Sánchez Amado, 2014; VVAA, 2016).

En Cantabria, en 2018, comenzó un proyecto de activación social y laboral con sectores vulnerables, preferentemente perceptores de rentas mínimas, con vocación de comenzar una línea orientada a la integración de servicios. Se gestiona a través de una entidad contratada a la que tanto los servicios sociales municipales como la Agencia de Empleo derivan a las personas usuarias simultáneamente. En la actual legislatura, en la que servicios sociales y empleo coinciden en la misma consejería, se pretende potenciar esta línea de integración y que sea asumida por el órgano regional de gestión de los servicios sociales, el Instituto Cántabro de Servicios Sociales (ICASS), y por el Servicio Cántabro de Empleo.

En Murcia se elaboró un protocolo de coordinación para mejorar la inserción sociolaboral de personas en situación o riesgo de exclusión social, con especiales dificultades de inserción en el mercado de trabajo, para simplificar las derivaciones y utilizar herramientas compartidas entre el Servicio Regional de Empleo y Formación de la Región de Murcia (SEF), el Instituto Murciano de Acción Social (IMAS), la Dirección General de Familia y Políticas Sociales, los Servicios Sociales de Atención Primaria y las entidades del tercer sector (Hernández Pedreño y Manzanera-Román, 2019). Se han establecido herramientas comunes entre las que destaca la acreditación de la situación de exclusión o la valoración de la empleabilidad por parte de los servicios sociales de atención primaria (SSAP), que debe dar lugar a las correspondientes actuaciones por parte del servicio público de empleo (SEF). En los procesos de derivaciones están contempladas también las entidades de iniciativa social (EIS). 
En la evaluación realizada sobre su funcionamiento, se recoge una valoración positiva en cuanto al trabajo profesional en la mayoría de los casos ( $78 \%$ de profesionales del SEF, $62 \%$ del SSAP y $59 \%$ de las EIS). El balance era también positivo en cuanto al impacto en las personas usuarias, con un aumento de la activación, la presencia en actividades formativas y el número de derivaciones entre entidades. Sin embargo, su aplicación era parcial (el $39 \%$ de los SSAP no utiliza la herramienta de valoración de la empleabilidad), y el modelo burocrático de derivaciones suponía un trabajo extra para los profesionales, una cierta confusión y duplicidad de funciones (Martínez García, 2018).

Más extendidas en las diferentes CCAA están las prácticas, con distintas variaciones, en las que se produce una cierta convergencia e integración de actuaciones sociales y de empleo en el ámbito local, bien por las propias entidades locales, bien por entidades de iniciativa social. Unas y otras, persiguiendo una intervención más integral con las personas beneficiarias, captan diversos recursos de las administraciones regionales, tanto de empleo como de tipo formativo o mixto (o incluso educativos), y los articulan con las intervenciones de los servicios sociales en el ámbito local, con la idea construir itinerarios coherentes de inclusión para las personas concretas con las que trabajan. Ejemplos de esto serían la experiencia de Valladolid, con su Servicio de Orientación y Asesoramiento Laboral (Prieto Lobato et al., 2019), o el programa Làbora del Ayuntamiento de Barcelona. En estos y en otros casos, se trata de un proceso de integración en la base que debe reconocerse y valorarse y que podría marcar una línea interesante de desarrollo de la integración de servicios, pero que, de momento, aparece muy condicionado por la fragmentación de las fuentes de financiación y la falta de articulación de las convocatorias, normalmente anuales, que encorseta el desarrollo de programas coherentes y estables.

En este contexto de experiencias de diversa intensidad, orientación y ámbito competencial, se entiende la iniciativa del antiguo Ministerio de Sanidad, Consumo y Bienestar Social de promover una red de inclusión social con el objetivo de impulsar la integración de los servicios sociales y de empleo, preferentemente en las CCAA. Con ese fin, se han puesto en marcha cuatro grupos de trabajo. El que más ha avanzado es el dedicado al intercambio de información entre ambos sistemas. Con un amplio consenso en cuanto a la necesidad de compartir e intercambiar información y de trabajar en herramientas compartidas, se han identificado las dificultades y los obstáculos (políticos, tecnológicos, técnicos y normativos), y también la información que tiene interés intercambiar. Desde esta red, se promueven una serie de proyectos piloto para "ofrecer una respuesta integral a las personas que necesitan apoyo para su inclusión activa, buscando la eficiencia de recursos mediante la gestión coordinada de los servicios sociales y los servicios de empleo».5 Carente sin embargo de la capacidad ejecutiva para poner en marcha directamente una iniciativa de calado nacional y sin un soporte de peso político suficiente,

5. Las conclusiones de los diferentes grupos de trabajo y el documento de referencia de los proyectos piloto pueden verse en http://redinclusionsocial.es/. 
el impacto real de esta red dependerá del nivel de implicación que quieran desarrollar las CCAA.

$\mathrm{Al}$ margen de estos proyectos o acciones específicas, no se registran reformas orientadas a la integración de servicios en el sentido indicado por las recomendaciones europeas en el marco de la estrategia de Inclusión Activa (European Commission, 2008), esto es, que todo programa de inclusión se sustente en combinaciones institucionales eficaces que garanticen una renta adecuada, el apoyo de servicios públicos de calidad en los campos de la sanidad, educación y servicios sociales, y programas que faciliten la incorporación en el mercado de trabajo. En ese sentido, el proyecto ERSISI, en Navarra, al que se hará referencia más abajo, ha resultado pionero en el Estado, al poner en marcha un proyecto piloto de integración que actualmente se encuentra en su fase de escalabilidad (RIS, 2020). Por eso, nos parece relevante analizar en profundidad y valorar los logros y los límites de la experiencia que más ha avanzado en esta línea de la integración de servicios, como es la de la Comunidad Foral de Navarra.

\section{Navarra, una reforma de orientación socialdemócrata: amplia protección e inclusión social activa centrada en la persona}

En Navarra, desde la pasada legislatura 2015-2019, los servicios sociales y las políticas activas de empleo dependen del mismo Departamento de Derechos Sociales. Esta coincidencia ha permitido reforzar los procesos de coordinación y de integración de las actuaciones que realiza la Dirección General de Inclusión y Protección Social (DGIyPS), por un lado, y el Servicio Navarro de Empleo - Nafar Lansare (SNE-NL), por otro. En este proceso, ha sido determinante la experiencia del proyecto ERSISI, financiado por el programa europeo de innovación social EASI de la UE, que ha desarrollado herramientas compartidas de valoración, ha articulado un sistema de información compartida y ha promovido un modelo de atención profesional flexible y adaptada, centrada en la persona. Pero las actuaciones realizadas han ido más allá del mismo proyecto al elaborar protocolos de derivación de casos y seguimiento de las actividades de inserción de los perceptores de RG por ambas agencias, desarrollar dispositivos de orientación para el empleo específicos para sectores vulnerables, introducir estímulos al empleo en el programa de renta garantizada y coordinar los programas de empleo protegido que ambas agencias han incrementado.

\subsection{La reforma de la renta garantizada}

En todo ello, ha sido un elemento fundamental la reforma de la renta garantizada, realizada a finales de 2016, que reconocía un doble derecho, a unos ingresos mínimos y a la inclusión social, ${ }^{6}$ y que ha dado lugar a una importante movilización de recursos orientados tanto al aumento de la protección

6. Ley Foral 15/2016, de 11 de noviembre, por la que se regulan los Derechos a la Inclusión Social y a la Renta Garantizada (BON, 2016). 
social como a la activación laboral. El gasto dedicado a la protección social se duplicó en 4 años, de 49 millones en 2014 a 103,5 millones en 2018, lo que permitió incrementar las cuantías en un 33,5\% (686€/mes de media en 2018) y la cobertura en un $60 \%$, hasta alcanzar las 12.773 unidades perceptoras en su punto más alto en marzo de 2018 (DGIyPS, 2020b). Todo ello, a partir de una reforma legal que aumentaba la cobertura, objetivaba los requisitos de concesión y reducía los condicionamientos. ${ }^{7}$ Esta mejora se inscribe en la dirección señalada por las instituciones europeas, que sitúan la garantía de ingresos como condición imprescindible para la puesta en marcha de iniciativas de inclusión social activa (European Commission, 2008). La relevancia de esta reforma puede verse en la evolución de los informes europeos, que en 2015 calificaban a Navarra en un segundo grupo de programas generalistas pero con criterios de elegibilidad restrictivos y cobertura bastante baja (Frazer y Marlier, 2016); más recientemente, en el informe de país para España de 2020, la Comisión valoraba que la renta garantizada estaba teniendo un efecto muy significativo en la reducción de la pobreza, con una ratio de cobertura estimada del $100 \%$, la más alta del conjunto de CCAA españolas (European Commission, 2020).

Este aumento tan significativo de la protección social de los colectivos más vulnerables estaba llamado a producir también una expansión de las políticas de activación. El modelo de activación estaba incluido expresamente en la nueva ley, como derecho a la inclusión — social, no exclusivamente laboral—, y se concreta en un programa personalizado ${ }^{8}$ que ha de ser «libremente convenido» con quien percibe la prestación. Más allá de la letra de la propia ley, el desarrollo de programas de inclusión deviene un elemento importante de legitimación social y política de la reforma, demandado por todos los actores sociales y políticos. Por otro lado, en la medida en que aumentaba para el sector público el coste económico del sostenimiento de la pobreza, aumentaba también el interés por acelerar los procesos de incorporación al empleo y la propia capacidad de financiar actividades alternativas a la RG con dichos fondos. Finalmente, como se ha expresado abiertamente en el debate europeo, los programas de

7. Ya se habían aumentado significativamente las cuantías en 2015 para revertir los recortes anteriores. En 2016, se amplió la cobertura a personas mayores de 65 años, se eliminó la exigencia de permiso de residencia, se facilitó el acceso de unidades familiares de mayor tamaño, con el aumento de la prestación económica correspondiente. El requisito de residencia efectiva en Navarra se redujo a un año para unidades familiares con menores o personas dependientes o con discapacidad. Se amplió también indefinidamente el tiempo de percepción de la misma, mientras se mantuviese la situación de necesidad que originó la demanda. Se eliminó el requisito de un compromiso de incorporación previo durante el primer año y se simplificaron los requisitos y documentos a presentar. El incumplimiento de la obligación de disponibilidad para el empleo supone la salida del programa, pero no hay penalización para volverlo a solicitar de forma inmediata, con lo que el tiempo real de pérdida de prestación se sitúa entre uno y tres meses, y se puede acceder de forma alternativa a las ayudas de emergencia social de los Servicios Sociales de Base puestas en marcha de forma paralela en 2015 si se considera necesario.

8. Solo obligatorio después del primer año de percepción de la RG. 
activación —el desarrollo de diversas actividades de formación y búsqueda de empleo- tienen un efecto también como mecanismo de control de posibles situaciones de abuso o de fraude manifiesto. En este sentido, el caso navarro es otro ejemplo de lo errónea que es la contraposición entre protección económica y activación, propia de algunos planteamientos conservadores, como si se tratara de elegir entre una cosa u otra. Como muy bien expresa la experiencia contrastada de los países nórdicos, cuanto más generoso es un sistema en la protección económica, más probable es que se desarrollen a su vez programas de activación ambiciosos.

\subsection{Los estímulos al empleo de la renta garantizada}

Desde su aprobación en 2016, la renta garantizada en Navarra incorpora un mecanismo de estímulos al empleo que prevé ingresos totales comparativamente más altos para las unidades familiares que trabajan. Si los ingresos por trabajo son iguales o menores a $318 €$, no se restan de la cuantía de la RG, se acumulan ambas (si se trata de empleos protegidos, se reduce a $106 €$ ). Si son superiores, se va reduciendo progresivamente la $\mathrm{RG}$ hasta que los nuevos ingresos alcanzan los $1.026 €$ para una persona (hasta los $1.733 €$ para unidades de seis o más miembros). La progresividad se calcula con esta fórmula:

Renta garantizada $=\{(\mathrm{A} \times 600)+\{10 \times[($ Ingresos $/ 100)-2]\}\}-$ Ingresos

El mecanismo de «estímulos al empleo» no solo permite compatibilizar ingresos de la prestación con ingresos por renta del trabajo, sino que apunta a prevenir el eventual desincentivo a aceptar empleos, dado que en muchos casos los ingresos provenientes de la RG son más altos que los salarios ofrecidos. Su objetivo es que «trabajar resulte rentable» (make work pay) en términos de estímulo positivo y no de penalización de comportamientos alternativos.

En su primera fase, los estímulos al empleo se aplican exclusivamente a los ingresos sobrevenidos para los perceptores de RG, después de su incorporación. Se pretende un estímulo inmediato, con una duración limitada de un año. Esta fase es la que ya se ha aplicado y está en vigor actualmente. Posteriormente, deberán extenderse ${ }^{9}$ a todos los ingresos por trabajo de los perceptores y también, de forma similar, mediante deducciones fiscales reembolsables, a los trabajadores situados inmediatamente por encima del baremo de RG, para evitar así el efecto umbral.

Los estímulos al empleo benefician a 3.848 unidades familiares, una de cada cuatro, y exigen un intercambio permanente de información con los servicios de empleo y la asunción de objetivos comunes de incorporación laboral por parte de los servicios sociales. La puesta en marcha de las siguientes fases requerirá la implicación además del Departamento de Hacienda en la gestión de las deducciones fiscales reembolsables.

9. De acuerdo con la LF 15/2016, deberían haberse extendido ya en dos fases subsiguientes. 
Por otra parte, la gestión de un modelo de estímulos como el actual, para que sea efectivo en un mercado de trabajo hiperflexible en su extremo más precario, requiere un sistema muy ágil, que permita modificaciones inmediatas en las cuantías, tanto en la entrada como en la salida del empleo. Así, en 2019 se produjeron 8.104 modificaciones en las cuantías, lo que supone un $52 \%$ del total de unidades perceptoras en el año. Algo más de la mitad de las mismas fue por incorporación al empleo de algún miembro de la unidad perceptora.

La ley prevé también, como otra forma de incentivo al empleo, un mecanismo de suspensión de la prestación por incorporación al empleo que permite la reincorporación inmediata una vez que finaliza el contrato. Más de medio millar de unidades perceptoras se han beneficiado de esta vía en 2019 y un total de 1.293 se han dado de baja por incorporación laboral.

La rapidez de la gestión es un prerrequisito en sí mismo para todos estos incentivos, especialmente en mercados de trabajo muy flexibles, con muchos contratos de corta duración. En el caso de Navarra, hace una década, en 2011, el tiempo de valoración de un expediente desde su entrada en registro era de casi 4 meses, y de 2,3 meses en 2015. Después de la reforma, el tiempo se ha reducido a unos 20 días, lo que permite que los solicitantes perciban la prestación en el mes que les corresponde (al mes siguiente de la solicitud, según la ley), sin necesidad de contar con los sistemas de anticipos que se gestionaban anteriormente con Cáritas Diocesana.

\subsection{Herramientas compartidas de valoración}

La gestión de la información representa un desafío mayor cuando hablamos de integración de servicios y de población en exclusión social, por el carácter multidimensional, dinámico y de intensidad variable de esta (Laparra et al., 2007).

El diagnóstico social representa un elemento central en los procesos de definición de acciones e itinerarios, tanto en los servicios sociales como de empleo (Desiere et al., 2019; Felgueroso et al., 2018; Manzano et al., 2019)

En el marco del proyecto ERSISI se ha desarrollado el Sistema de Información del Derecho a la Inclusión Social (SIDIS), ya operativo en toda Navarra, con el objeto de unificar la práctica profesional y facilitar el ejercicio del derecho a la inclusión. SIDIS incorpora, entre otras, las siguientes funcionalidades: codiagnóstico social, con una escala de valoración ${ }^{10}$ que arroja como resultado cinco niveles — desde la inclusión social a la exclusión social grave- y que permite identificar tanto áreas de mejora individuales y sociorelacionales como capacidades de las personas. El Programa Personalizado de Inclusión Social (PPIS) detalla el itinerario de inclusión con sus objetivos, recursos y plazos reflejados en un convenio de inclusión social; una evaluación de la intervención, que consiste

10. La escala utilizada es una adaptación de la herramienta de diagnóstico social y valoración de exclusión desarrollada por el Departamento de Empleo y Políticas Sociales de la Comunidad Autónoma del País Vasco: https://bit.ly/397U3IU [visitado el 23/03/2020]. 
en una comparación entre la valoración inicial con la situación de la persona una vez finalizado el itinerario.

En lo referido a la integración de servicios, se ha desarrollado una réplica de SIDIS para el sistema de información de Empleo, Orientasare, que también contiene una herramienta de diagnóstico de valoración de la empleabilidad - con una escala que va desde alta a muy baja empleabilidad - y permite la asignación de acciones y recursos a cada persona.

Para definir con precisión los perfiles poblacionales que requieren de ambos servicios, y con el objetivo de ganar mayor eficacia en las intervenciones, desde el Departamento de Derechos Sociales se ha diseñado una herramienta de triaje o cribado, actualmente en fase de desarrollo, que estará alojada tanto en SIDIS como en Orientasare, el sistema informático del Servicio Navarro de Empleo. Siguiendo los modelos utilizados en el ámbito sanitario, esta herramienta formaliza un procedimiento de identificación de perfiles, basado en doce indicadores, dentro del conjunto de personas que acceden a los servicios. Su objetivo es clasificar, en función de un conjunto de necesidades y capacidades de las personas, los perfiles que requieren la atención de los servicios sociales o de empleo específicamente, o bien que necesitan una atención conjunta de ambos servicios.

De esta forma, cuando a través de la herramienta de triaje se identifique un perfil de atención integrada, independientemente de cuál sea el servicio de «entrada», se activará una ventana conjunta por la que ambos servicios compartirán la información necesaria para planificar, llevar a cabo y evaluar un itinerario de inclusión personalizado de manera coordinada. ${ }^{11}$ De esta forma, se materializa el procedimiento del derecho a la inclusión social tal como lo establece su decreto reglamentario (BON, 2018).

Así pues, manteniendo la especificidad organizativa de cada sistema, la disponibilidad de información compartida y de herramientas comunes es una vía para prestar una atención más integrada identificando específicamente los perfiles con los que ha de trabajarse conjuntamente y compartiendo la información de las actuaciones realizadas en cada caso.

\subsection{Protocolos de derivación}

A partir de 2018, ambas unidades administrativas (la Dirección General de Inclusión y Protección Social y el Servicio Navarro de Empleo - Nafar Lansare) acordaron una serie de protocolos de derivación y seguimiento específicamente para las personas perceptoras de renta garantizada, principalmente para la derivación al programa de orientación laboral del SNE-NL y para la gestión y el seguimiento de las ofertas de empleo realizadas a las mismas (Departamento de Derechos Sociales, 2020).

11. Actualmente, tanto la herramienta de triaje como la ventana conjunta se encuentran en fase de desarrollo, por lo que se aplican a un número reducido de casos para testar su funcionamiento y ampliarlas luego a todo el territorio. 
En el primer caso, desde la DG de Inclusión y Protección Social, responsable de la gestión de la RG, se transfiere periódicamente el listado de personas perceptoras con un año o más de antigüedad en el programa. Desde el Servicio Navarro de Empleo se cita a todas las que en principio están en condiciones de trabajar, de acuerdo con una primera valoración de los Servicios Sociales de Base, para participar en el programa de orientación. Esta es una iniciativa proactiva que nunca antes se había desarrollado desde los servicios de empleo. Además, al programa de orientación profesional se han incorporado entidades especializadas en los distintos sectores más vulnerables (jóvenes, personas con discapacidad, población gitana, mujeres...) y con objetivos específicos de atención a perceptores de RG. Posteriormente, desde el SNE-NL, se realiza un seguimiento de la respuesta de las personas participantes (localización, disponibilidad, asistencia y finalización de la orientación), y los resultados son comunicados a la DGIyPS, que puede actuar suspendiendo o extinguiendo la prestación en caso de incumplimiento. En su conjunto, puede observarse un aumento claro en la utilización de los servicios de empleo por parte de perceptores de RG: si antes estas derivaciones eran bastante excepcionales y ni siquiera se registraban, en 2019, según datos del Observatorio de la Realidad Social, ha habido 3.417 actuaciones de información y orientación profesional con población en RG, lo que supone un 17,4 \% del total de personas usuarias del programa de orientación y una actuación por cada 3,8 personas en 2019, de modo que todavía existe margen para ampliar este programa conjunto. Se ha apreciado también una mejora notable en la disponibilidad para el contacto telefónico (actualización del número, respuesta a la llamada...). En los casos atendidos desde el Servicio de Orientación, se ha realizado un diagnóstico individualizado para identificar sus competencias, formación y experiencia, se ha diseñado un itinerario personalizado para el empleo, se ha facilitado información sobre mercado de trabajo y, en general, se ha prestado apoyo en aquellos procesos que les puedan ayudar en la búsqueda de empleo.

Un elemento a mejorar aquí es la continuidad de la atención y el paso a los subsiguientes recursos por parte de la población beneficiaria, que todavía no está garantizado en el procedimiento de orientación y que puede llevar a que los procesos de inclusión se interrumpan y se pierda el hilo de la intervención por parte de los dos sistemas, con una subsiguiente pérdida de eficiencia y una previsible necesidad de volver a repetir ciertos procesos en el futuro (nuevos diagnósticos, seguimientos, etcétera).

En el caso de las ofertas de empleo, se ha acordado un registro común en ambos sistemas de las personas que no se encuentren en situación de incorporarse al mercado laboral ni a un empleo protegido, de acuerdo con el diagnóstico inicial de los Servicios Sociales de Base, de tal forma que no se canalicen a estas personas a ofertas de empleo que podrían poner en cuestión su derecho a la protección social. En los casos en que las personas están en condiciones de trabajar, el protocolo prevé el seguimiento por parte del SNE-NL de las ofertas de empleo que son transmitidas a personas perceptoras de RG, tanto aquellas ofertas de carácter genérico como las que se realizan específicamente en 
el marco de programas de empleo protegido dirigidos a personas perceptoras, que han experimentado un crecimiento significativo en estos años, como puede verse en el punto siguiente. El resultado de ese seguimiento es comunicado de forma individualizada tanto a la DGIyPS como al Servicio Social de Base al que está adscrita la unidad perceptora.

Estos protocolos han sido la respuesta que ambos sistemas han construido conjuntamente (más allá de las actuaciones de los servicios sociales de atención primaria) para hacer efectivo el principio de activación previsto en la Ley Foral 15/2016 de Derecho a la Inclusión Social y a la Renta Garantizada, que recoge explícitamente la obligación de estar disponibles para un empleo adecuado, y de aceptarlo cuando se les ofrezca, para aquellas personas que estén en condiciones de trabajar. Al ser una respuesta que ya se ha construido técnicamente y sobre la que ya hay una experiencia acumulada, ahora debería formalizarse con la elaboración del reglamento oportuno que fuese imperativo para ambos sistemas.

\subsection{Los programas de empleo protegido del SNE y de los servicios sociales}

La Ley Foral 15/2016, tanto en su denominación como en el orden del articulado o en el énfasis del preámbulo, antepone el derecho a la inclusión social y entiende que esa inclusión debe pasar mayoritariamente por la incorporación al mercado de trabajo de aquellas personas que están en condiciones de trabajar. El texto va todavía más allá y reconoce, después de dos años en el programa, el derecho (y la obligación de las administraciones públicas) de que se les ofrezca un empleo (o un programa de formación y empleo) y también la obligación de aceptarlo, como veíamos antes.

Por ello, de forma paralela al desarrollo de las prestaciones económicas que hemos visto antes, se han expandido también distintos programas de empleo protegido dirigidos de una forma u otra a personas perceptoras de RG. Diversos análisis venían mostrando el interés técnico de este tipo de dispositivos, desde las formulaciones más antiguas de los campos de trabajo (Aguilar et al., 1995; Laparra et al., 1989) hasta las revisiones más recientes de sus fórmulas actuales, que han destacado la mayor dimensión y alcance, en términos de cobertura y estabilidad que estos programas tienen en Navarra (Martínez Virto, 2017). En esta estrategia, también han coincidido los servicios sociales, con su programa de empleo social protegido, y los servicios de empleo, con las subvenciones a entidades locales para contratación de desempleados. Si se quería potenciar estos recursos de inserción laboral, había que coordinar y articular más sus actuaciones.

El empleo social protegido es gestionado por los Servicios Sociales de Base y financiado desde los presupuestos de servicios sociales del Gobierno de Navarra. Este programa implica la contratación laboral de las personas beneficiarias entre 6 y 12 meses y prevé actuaciones complementarias de formación y de acompañamiento social. A partir de 2016, se produce un incremento significativo del presupuesto del $30 \%$, hasta los 6,5 millones (incluida también la 
variante gestionada por entidades sociales), lo que permite aumentar el número de personas usuarias y el tiempo de contratación. Además, a partir de 2017 se incrementa la proporción obligatoria de población de RG que participa en el mismo hasta el $90 \%$, hasta alcanzar un $96 \%$ en 2018, sobre un total de 777 personas. Ya en 2020, el nuevo Decreto Foral de Servicios Sociales de Base prevé la estabilización de los fondos dedicados a profesionales de apoyo, que pasan a considerarse parte del equipo de inclusión social de los mismos.

Desde el Servicio Navarro de Empleo - Nafar Lansare, se viene desarrollando históricamente, como en otras CCAA, un programa de subvenciones a las entidades locales para la contratación de personas desempleadas en obras y servicios de interés general. En estos programas, no se prevén actuaciones complementarias de formación o acompañamiento social a las personas contratadas. Al estar menos alineados históricamente con las políticas de inclusión, la proporción de personas perceptoras de rentas mínimas que participaban en los mismos venía siendo muy reducida (del 6,4 \% en Navarra en 2015). Un mayor alineamiento de estos dos programas (gracias a la reforma del programa de orientación laboral y los protocolos de derivación) ha logrado que la proporción se haya quintuplicado, hasta el $27,4 \%$, a lo que hay que añadir el incremento general de fondos de un $46 \%$, hasta los 4,1 millones.

Tanto en estos programas como en otros de similar orientación laboral (las subvenciones a la contratación de personas perceptoras de RG o el acceso a las empresas de inserción ${ }^{12}$ ), ha sido necesario construir una dinámica de colaboración e información fluida para la identificación de la población de RG que pueda incorporarse a los mismos, bien por el hecho de serlo, bien a través de un informe específico desde los servicios sociales. A su vez, la incorporación a los programas de empleo protegido supone también la gestión inmediata del cambio pertinente respecto de la RG (suspensión o reducción de la cuantía, aplicación de los incentivos al empleo, entre otras). El hecho de que se gestionen programas de empleo protegido tanto desde el servicio público de empleo como desde los servicios sociales no genera una especial controversia en la asunción de que todos los recursos son bien recibidos para esta finalidad. Entre 2015 y 2018 el total del presupuesto para estos programas de empleo protegido aumentó un $60 \%$, hasta los 14,5 millones. Aun con ese crecimiento, el número de puestos de trabajo en inserción todavía es insuficiente para garantizar el derecho al empleo que reconoce la ley.

\subsection{El modelo de atención integrada del proyecto ERSISI: atención profesional flexible y adaptada, centrada en la persona}

El proyecto ERSISI, dentro del Programa Europeo de Empleo e Innovación Social (EaSI), ha puesto a prueba un modelo de intervención que debía acom-

12. Con 240 personas beneficiarias, han pasado de 1,7 a 3 millones de euros en 4 años, después de proceder a su reconocimiento en 2016, y ya en 2020 se ha aprobado un segundo decreto orientado a hacer posible su crecimiento futuro. 
pañar el reconocimiento de los derechos a la inclusión social y a la renta garantizada y el aumento de la protección en ambos aspectos. En concreto, se ha podido poner a prueba el modelo de activación para el empleo en un marco de protección económica más seguro para las personas.

El proyecto tenía también por objetivo la adaptación de los recursos y medidas de activación para el empleo a las necesidades y características de las personas y el territorio. Los modelos de atención centrados en la persona, frente a otros modelos tradicionalmente diseñados desde el enfoque de los servicios, buscan adecuar los recursos de intervención (acciones formativas, ayudas de transporte, ayudas de conciliación, etcétera) a las necesidades e intereses de las personas. Para ello se precisa de recursos flexibles y adaptables a situaciones diversas (Fuertes y Lindsay, 2016), con participación en el ámbito local y la coordinación entre diferentes agencias (servicios sociales, empleo, educación), pero también de diferentes tipos de actores (públicos y privados) y, principalmente, niveles de gobierno (gobernanza multinivel).

El modelo de atención integrada para personas en riesgo de exclusión social aplicado desde los servicios sociales y de empleo, sobre la base de la técnica de gestión de casos y desde el enfoque de la atención centrada en la persona, pone el énfasis en sus fortalezas y en la autodeterminación personal. Esta intervención, que ha sido probada con 502 individuos, ha consistido en el trabajo de cuatro equipos de gestión de casos, en Tudela y Alsasua. ${ }^{13}$ Estos equipos han estado conformados por parejas de profesionales con un perfil orientado al empleo y otro a la intervención social.

Esta atención integrada llevada a cabo en ERSISI es coherente con la concepción consensuada de los itinerarios de inclusión social recogida en la LF $15 / 2016$. Esto supone una atención individualizada en la que se considera a las personas como agentes activos, con capacidad de determinación en el proceso de intervención. Se trata de un proceso que reconoce no solo las necesidades, sino las fortalezas y potencialidades del individuo, y contempla sus expectativas y sus tiempos.

Además de la instancia de codiagnóstico, la utilización de planes personalizados en el proceso de intervención, con su traslado a la herramienta informática (SIDIS), ha sido uno de los elementos centrales del modelo de atención integrada y, además, se ha convertido en el principal instrumento en el que se han volcado los esfuerzos por dar contenido al carácter personalizado de las intervenciones, es decir, adecuar la atención a los intereses y las motivaciones de las personas participantes. Esto último supone un cambio notable en la relación establecida entre los sujetos involucrados en la intervención. Además, esta ha

13. El proyecto ERSISI se aplicó en dos zonas básicas de servicios sociales, Tudela y Alsasua, especialmente castigadas por el desempleo en la crisis 2008-14, aunque con niveles muy distintos de desigualdad y pobreza (casi el doble de pobreza severa en Tudela entonces), y muy distintas también en cuanto a estructura del mercado de trabajo (más industrial, Alsasua; con más peso de la agricultura y los servicios, Tudela), además de otras diferencias lingüísticas y culturales. Ambas zonas suponen el 7 \% de la población de Navarra, con 996 perceptores de renta garantizada en 2016, año de comienzo del proyecto. 
Miguel Laparra; Laureano Martínez Sordoni

sido una herramienta valorada muy positivamente por parte de la dirección técnica del proyecto y los equipos de gestión de casos (DGIyPS, 2019).

\subsection{Primeros resultados que se constatan de este proceso de reforma y experimentación}

La evidencia empírica disponible hasta el momento apunta a un impacto positivo de las reformas llevadas a cabo, tanto en términos generales de regulación del programa como en cuanto a los cambios metodológicos y organizativos que introduce el proyecto ERSISI de forma experimental.

En términos de resultados generales de la reforma de la renta garantizada en Navarra, el aumento en la protección social (aumento de cuantías y de cobertura) y la flexibilización de los condicionamientos para el acceso y mantenimiento en el programa fueron compatibles con un aumento en la inserción en el empleo de las personas perceptoras: entre 2016 y 2019 se duplicó el número de unidades familiares con ingresos por trabajo, hasta llegar al 35,6 \%, con un aumento de las personas contratadas del 23,5\% (DGIyPS, 2020b). Como resultado de ambas cosas, y en un contexto de creación de empleo, la pobreza severa se redujo (entre 2015 y 2018, último dato disponible, entre un $9 \%$ y un $23 \%) .{ }^{14}$ Todos estos datos ponen de manifiesto la mejora en la estrategia de protección social e inclusión activa, que ha ido en paralelo con la estrategia de intervención conjunta por parte de los servicios sociales y de empleo que hemos presentado aquí.

También es importante la valoración que hace la propia población participante en el proyecto ERSISI de la atención recibida. Cerca de un $48 \%$ ha manifestado que está «muy de acuerdo» en que los servicios recibidos se han adaptado a sus necesidades, al tiempo que otro $32,4 \%$ se ha declarado «de acuerdo» en esta misma afirmación. Aun siendo así, todavía un porcentaje significativo de las personas encuestadas - $18,4 \%$ - señalan estar «muy en desacuerdo» o «en desacuerdo» en este aspecto, tratándose posiblemente de perfiles que no se encontraban en situación de recibir un proceso de intervención intensivo, o bien que no encontraron una respuesta adaptada a sus expectativas. En la valoración del grupo de control, el nivel de insatisfacción frente a los servicios «tradicionales» se llega a triplicar: un 51,4 \% señala estar «muy en desacuerdo» o «en desacuerdo» con la adaptación de la intervención a sus circunstancias personales. El modelo de intervención integrada y centrada en la persona consigue de este modo invertir la percepción de las personas que reciben el servicio.

Las personas usuarias han valorado también su participación en la toma de decisiones a lo largo del proceso de intervención. En este caso, el 65,7 \% de las

14. Bajo el $40 \%$ de la mediana de ingreso familiar equivalente de cada año o anclada en el primer año (con umbral regional), según la Estadística de Renta de la Población de Navarra de Nastat. Observatorio de la Realidad Social (2020). «IV Informe sobre la pobreza y la desigualdad social en Navarra». Pamplona: Gobierno de Navarra. 
personas consultadas manifiestan con rotundidad que se ha tenido en cuenta su voluntad en los procesos de toma de decisiones. Otro $24 \%$ se muestra «de acuerdo" con este hecho. Se trata sin duda de un resultado muy positivo. La inmensa mayoría de las personas participantes se han sentido involucradas en el proceso de toma de decisiones. La diferencia con el grupo de control es drástica: más de un $45 \%$ de las personas encuestadas consideran que no han sido partícipes en los procesos de toma de decisiones. Estos resultados son de gran relevancia, puesto que es sabido que una mayor satisfacción con los servicios recibidos supone mayor implicación (como ya se ha visto) y mejores resultados (pendientes de evaluación definitiva).

Los resultados muestran un impacto positivo en la activación para el empleo, entendida como la participación en acciones de orientación, formación y búsqueda de empleo. Este resultado es de gran relevancia, dado que el diagnóstico del proyecto arrojaba una muy baja participación de las personas perceptoras de rentas mínimas en acciones de activación para el empleo. En concreto, la media semestral de acciones de orientación y formación pasó de 1 en el semestre previo a la intervención a 9 durante la intervención y a 5 en el semestre posterior, lo que indica una significativa persistencia de la activación. Al compararlo con el grupo de control, la diferencia neta es de una mejora de 3 acciones en la media semestral posterior a la participación en el proyecto. En ese sentido, los resultados permiten afirmar que la integración de servicios resulta una medida eficaz a la hora de concretar la dimensión de la inclusión activa referida a garantizar los servicios de apoyo orientados a la reinserción en el mercado de trabajo.

En cuanto a la inserción laboral, los resultados no son todavía concluyentes, ya que el proyecto experimental finalizó a finales de 2019. A partir de la evaluación realizada con técnicas contrafactuales, se sabe ya que el impacto específico del proyecto en los seis primeros meses tiende a cero, lo cual coincide con otras experiencias, como las analizadas en el estudio de David Card, Jochen Kluve y Andrea Weber (2018), que identifican impactos muy reducidos en el corto plazo. Sin embargo, a raíz de estas mismas referencias, cabe esperar que pueda demostrarse un impacto positivo a medio y largo plazo, a la luz del resto de evidencias recogidas.

Con estos resultados, parece razonable la extensión y profundización de esta estrategia, más allá de las actuaciones ya realizadas. De hecho, ha comenzado ya la transferencia del modelo de atención integrada del proyecto ERSISI a otras localidades (Huarte, Villaba y Burlada) y se prevé que, posteriormente, con las modificaciones oportunas, se traslade al conjunto de Navarra (DGIyPS, 2020a). Junto a esta institucionalización del modelo de atención integrada, las herramientas de diagnóstico y de transmisión de información entre los dos sistemas, así como los protocolos de derivación, siguen desarrollándose actualmente. Así, tal como se recoge de otras experiencias internacionales, se ha optado por implementar estas reformas en proyectos piloto y escalarlas posteriormente en base a las evidencias recogidas (Scharle, 2018). 


\section{Conclusiones}

A pesar de las recomendaciones de la Comisión Europea y de la literatura especializada, y a pesar de tener un millón de personas atendidas en común, 640.000 de ellas en situación de dificultad, en España se ha avanzado poco en la integración de los servicios sociales y de empleo. Hemos podido identificar diversas iniciativas, tanto desde la Administración central como desde algunas CCAA y también en el ámbito local, pero en la mayoría de los casos se trata de experiencias incipientes (como Murcia, que ha comenzado a diseñar algunos protocolos de derivación) o parciales (como el País Vasco, que no ha incorporado a los servicios sociales en el proceso).

En el ámbito estatal, en el debate sobre la responsabilidad de la gestión de las rentas mínimas entre servicios sociales y empleo, el contraste de la experiencia de Navarra con otras como el País Vasco, donde se gestiona desde los servicios de empleo, u otras CCAA donde se gestiona totalmente al margen de estos, también nos deja algunas enseñanzas. Más allá de la responsabilidad de la gestión de la prestación por un sistema u otro, la clave es la existencia de un volumen importante de personas que requieren de la intervención conjunta de ambos sistemas. El debate sobre las rentas mínimas no es competencial, sino de coordinación. Lo importante es conseguir la implicación de ambos sistemas en la atención a estos colectivos más vulnerables. La aprobación en 2020 de un Ingreso Mínimo Vital en España y su previsible expansión progresiva, ponen de relieve la importancia de este debate.

En este momento, podemos identificar a Navarra como la comunidad autónoma donde más se ha avanzado en un proceso progresivo de integración de actuaciones entre los servicios sociales y de empleo. Además del desarrollo de un proyecto experimental del programa europeo EaSI durante tres años, específicamente orientado a la integración de los servicios sociales y de empleo (ERSISI), se han desarrollado herramientas compartidas de valoración, se han puesto en marcha protocolos de derivación y de trabajo conjunto, dispositivos de orientación laboral para sectores vulnerables o estímulos al empleo en el programa de renta garantizada; se han alineado los programas de empleo protegido desarrollados por ambas agencias y se ha promovido un modelo de atención profesional flexible y adaptada, centrada en la persona. La coincidencia en un mismo departamento de ambas competencias, el desarrollo del proyecto ERSISI y el proceso paralelo de reforma de la renta garantizada, con un modelo de reconocimiento del doble derecho, a la protección económica y a la inclusión social y laboral, han sido las claves de estos avances durante los últimos años.

Aunque en el análisis internacional se han puesto de relieve las potencialidades de los procesos de reforma e integración de servicios más radicales y ambiciosos (unificando los servicios) para potenciar la activación de la población perceptora de rentas mínimas, la experiencia de Navarra muestra que tiene interés también prestar atención a otras formas de integración progresiva que avanzan significativamente, sin sobresaltos, y que presentan importantes potencialidades para modelos institucionales multinivel más complejos. Al conjugar 
un aumento de los niveles de protección económica con mejoras en la inclusión social y laboral, y un resultado de reducción de la pobreza y la exclusión severa, ofrece un modelo de referencia para otras situaciones similares del sur de Europa. Esto puede ser de especial valor si se tiene en cuenta su desarrollo en un contexto estatal propio del modelo mediterráneo de estado de bienestar y con más problemas de calidad en la Administración Pública que en el centro y el norte de Europa.

En el debate en torno a las políticas de activación y los condicionamientos del acceso a prestaciones, que pueden llegar a limitar su capacidad protectora, resultan de gran relevancia los aportes del modelo navarro, con una concepción suave de la condicionalidad, basada en el acuerdo y el consenso, con escasas sanciones y un modo de atención centrada en la persona que se asemeja más a los modelos nórdicos basados en los valores socialdemócratas. En ese modelo, el desarrollo de la protección económica es un elemento que potencia y no reduce los programas de activación y, al revés, esta no reduce los ingresos de los sectores vulnerables, sino que los mejora con diversas fórmulas de incentivos al empleo y de empleo protegido.

En el contexto de ese debate, un modelo de intervención profesional centrada en la persona puede ser la clave para encontrar el equilibrio entre activación y protección. En este aspecto, si bien los avances de la experiencia de Navarra han sido significativos, también muestran los obstáculos y los desafíos que quedan por delante. En primer lugar, estos cambios requieren continuidad y, por tanto, compromisos políticos a medio o largo plazo: una discontinuidad en el proceso de transferencia podría diluir fácilmente los logros conseguidos. Cuando los resultados no son inmediatos, la dinámica del proceso no siempre encaja en los tiempos políticos. En segundo lugar, destaca el desafío de incorporar a la pluralidad de actores institucionales que inciden en las políticas de inclusión. En este punto, queda pendiente una mayor implicación de los empleadores en los programas de activación. Por último, la relevancia de las experiencias locales y regionales puede verse comprometida si no hay una adecuada coordinación por parte del Estado, y si las reformas en marcha en garantía de rentas (con el nuevo Ingreso Mínimo Vital), en las políticas de activación para el empleo y de inclusión activa no reconocen las experiencias autonómicas y locales y no se articulan adecuadamente con ellas.

\section{Agradecimiento}

Este artículo es producto del proyecto ERSISI, Enhancing the Right to Social Inclusión through Service Integration (VS/2016/0209), cofinanciado por el programa Employment and Social Innovation EaSI, de la Comisión Europea, y coordinado por el Departamento de Derechos Sociales del Gobierno de Navarra. 


\section{Referencias bibliográficas}

Aguilar, M.; Gaviria, M. y Laparra, M. (1995). La caña y el pez: el salario social en las comunidades autónomas 1989-1994. Madrid: Cáritas Española Editores.

Álvarez Rosete, A. (2020). Cinco años de atención integrada en España (OMIS 20142019). Fundación New Health.

Askim, J.; Fimreite, A. L.; Moseley, A. y Pedersen, L. H. (2011). «One-stop shops for social welfare: The adaptation of an organizational form in three countries». Public Administration. <https://doi.org/10.1111/j.1467-9299.2011.01933.x>

BON (2016). «Ley foral 15/2016, de 11 de noviembre, por la que se regulan los derechos a la inclusión social y a la renta garantizada». Boletín Oficial de Navarra, 223.

- (2018). «Decreto foral 26/2018, de 25 de abril, de desarrollo de los derechos a la inclusión social y a la renta garantizada».

Bonoli, G. (2013). The Origins of Active Social Policy. Labour Market and Childcare Policies in a Comparative Perspective. Oxford: Oxford University Press.

Card, D.; Kluve, J. y Weber, A. (2018). "What works? A meta-analysis of recent active labor market program evaluations». Journal of the European Economic Association, 16 (3). <https://doi.org/10.1093/jeea/jvx028>

Catalano, S. L.; Graziano, P. R. y Bassoli, M. (2016). "The local governance of social inclusion policies in Italy: working via "organ pipes"». En: HeIDENRICH, M. y Rice, D. (eds.). Integrating Social and Employment Policies in Europe Active Inclusion and Challenges for Local Welfare Governance. Cheltenham: Edward Elgar.

Champion, C. y Bonoli, G. (2011). «Institutional fragmentation and coordination initiatives in Western European welfare states». Journal of European Social Policy, 21 (4), 323-334.

Consejo Europeo (2014). «Recomendación del Consejo relativa al Programa Nacional de Reformas de 2014 de España y por la que se emite un dictamen del Consejo sobre el Programa de Estabilidad de España para 2014 (2014/C 247/08)». Diario Oficial de la Unión Europea.

Departamento de Derechos Sociales (2020). «Protocolo de seguimiento y control de la obligación de mantenerse disponible para el empleo adecuado».

Desiere, S.; Langenbucher, K. y Struyven, L. (2019). "Statistical profiling in public employment services: An international comparison». Social, Employment and Migration Working Papers, 224. <https://doi.org/https://doi.org/10.1787/1815199X>

DGIyPS (2019). «Informe de evaluación del proyecto ERSISI».

- (2020a). «Evaluación de la transferibilidad de ERSISI».

- (2020b). «Renta Garantizada. Balance 2019».

European Commission (2008). «Commission Recommendation of 3 October 2008 on the active inclusion of people excluded from the labour market».

- (2020). «Country Report Spain 2020 accompanying the Communication from the Commission".

Felgueroso, F.; García-Pérez, J. I. y Jiménez-Martín, S. (2018). Perfilado estadístico: un método para diseñar políticas activas de empleo. Editorial Centro de Estudios Ramón Areces.

Fernandez, R.; Immervoll, H.; Pacifico, D. y Thévenot, C. (2016). Faces of Joblessness: Characterising Employment Barriers to Inform Policy. París: OECD Papers Series. <https://doi.org/10.1787/1815199X> 
Ferran Zubillaga, A.; Guinot Viciano, C. y Berasategui Otegui, A. (2019). Gobernanza colaborativa para la inclusión social. Una experiencia de investigación y acción participativa. Madrid: Libros de la Catarata.

Fletcher, D. R. (2020). "Introduction to the Special Edition». Social Policy and Administration, 54 (2), 185-190. <https://doi.org/10.1111/spol.12569>

Frazer, H. y Marlier, E. (2016). Minimum Income Schemes in Europe. A study of national policies (Issue January). Luxemburgo: Publications Office of the European Union. <https://doi.org/10.2767/860513>

Fuertes, V. y LindSAY, C. (2016). «Personalization and street-level practice in activation: the case of the UK's work programme». Public Administration, 94 (2), 526-541. <https://doi.org/10.1111/padm.12234>

Garcés, J. y Ródenas, F. (2015). «La gestión de casos como metodología para la conexión de los sistemas sanitario y social en España». Atención Primaria, 47 (8), 482-489. <https://doi.org/10.1016/j.aprim.2014.11.005>

Genova, A. (2008). «Integrated Services in Activation Policies in Finland and Italy: A Critical Appraisal». Social Policy and Society, 7 (3), 379-392. $<$ https://doi.org/10.1017/s147474640800434x>

González Gago, E. (2018). Spain / Basque Country. In Study on integrated delivery of social services aiming at the activation of minimum income recipients in the labour market-success factors and reform pathways. Part II: Annexes. Luxemburgo: Publications Office of the European Union.

Hernández Pedreño, M. y Manzanera-Román, S. (2019). "El modelo de inclusión social en la región de Murcia: trayectoria de las políticas de inclusión desde el año 1982 hasta el 2017. En: Pérez Eransus, B. y Martínez Virto, L. (eds.). Políticas de inclusión en España: Viejos debates, nuevos derechos. Madrid: Centro de Investigaciones Sociológicas.

Laparra, M.; Corera, C; Gaviria, M. Y Aguilar, M. (1989). El salario social sudado. Madrid: Popular.

Laparra, M.; Obradors Pineda, A.; Pérez Eransus, B.; Pérez Yruela, M.; Renes Ayala, V.; Sarasa Urdiola, S.; Joan, S. y Trujillo Carmona, M. (2007). «Una propuesta de consenso sobre el concepto de exclusión: implicaciones metodológicas». Revista Española del Tercer Sector, 5, 15-58.

Lara Montero, A.; Duijn, S. van; Zonneveld, N.; Minkman, M. y Nies, H. (2016). Integrated social services in Europe. A study looking at how local public services are working together to improve people's lives. Brighton: European Social Network.

Manzano, M. Á.; Pagés Gaulier, E. y Solé Pascual, M. (2019). «La DS-DIBA: experiencia de la elaboración de una herramienta de valoración social y segmentación para los servicios sociales». Cuadernos de Trabajo Social, 32 (1), 177-189.

Martínez García, V. (2018). Diagnóstico de situación de la aplicación del Protocolo de Coordinación para la mejora de la inserción sociolaboral de personas en situación o riesgo de exclusión social. Región de Murcia. Dirección General de Familia y Políticas Sociales

Martínez Virto, L. (2017). «Programas de Servicios Sociales para la inclusión social a través del empleo: ante el reto de la transversalidad, la multidimensionalidad y la creación de oportunidades laborales». Trabajo Social Global - Global Social Work: Revista de Investigaciones en Intervención Social, 7 (13), 95-117.

$<$ https://doi.org/10.30827/tsg-gsw.v7i13.5664> 
Minas, R. (2016). «The concept of integrated services in different welfare states from a life course perspective». International Social Security Review. <https://doi.org/10.1111/issr.12113>

Munday, B. (2007). Integrated Social Services in Europe. Bruselas: Council of Europe Publishing.

Observatorio de la Realidad Social (2020). «IV informe sobre la pobreza y la desigualdad social en Navarra». Pamplona: Gobierno de Navarra.

<https://www.observatoriorealidadsocial.es/es/estudios/iv-informe-sobre-la-pobreza-y-la-desigualdad-social-en-navarra/es-557052/>

OECD (2015). «Integrating Social Services for Vulnerable Groups: Bridging Sectors for Better Service Delivery». En: Integrating social services for vulnerable groups: bridging sectors for better service delivery. París: OECD Publishing.

Pérez Eransus, B. y Martínez Virto, L. (2020). Políticas de inclusión en España: viejos debates, nuevos derechos. Madrid: Centro de Investigaciones Sociológicas, CIS.

Prieto Lobato, J. M.; Rodríguez Sumaza, C. y Rosa Gimeno, P. de la (2019). «Las relaciones entre administraciones públicas y Tercer Sector en el marco de las políticas de inclusión social en Castilla y León». Investigaciones Regionales - Journal of Regional Research, 44, 63-79.

RIS (2020). «I Jornada. Hacia un nuevo modelo de prestación integrada de servicios de empleo y servicios sociales». Documento resumen de la jornada.

Rodríguez CABrero, G. (2011). Estudio comparado sobre estrategias de inclusión activa en los paises de la Unión Europea. Ministerio de Sanidad, Política Social e Igualdad. Centro de Publicaciones.

SAdeghi, T. y Terum, L. I. (2020). «Frontline managers' perceptions and justifications of behavioural conditionality». Social Policy and Administration, 54 (2), 219-235. <https://doi.org/10.1111/spol.12574>

Sánchez Amado, P. (2014). «La garantía de ingresos y los Servicios Sociales en Euskadi. 2011-2013». Servicios Sociales y Politica Social, 106, 81-94.

SCHARle, Á. et al. (2018). Study on integrated delivery of social services aiming at the activation of minimum income recipients in the labour market-success factors and reform pathways. Part I: study. Publications Office of the European Union.

VVAA (2016). La situación de los servicios sociales municipales en la Comunidad Autónoma de Euskadi. Ararteko. Defensoría del Pueblo.

Wright, S.; Fletcher, D. R. y Stewart, A. B. R. (2020). «Punitive benefit sanctions, welfare conditionality, and the social abuse of unemployed people in Britain: Transforming claimants into offenders?». Social Policy and Administration, 54 (2), 278-294. <https://doi.org/10.1111/spol.12577> 